\title{
EDITORIAL FOREWORD
}

\section{Writing a Publishable Research or Review Paper}

Especially young researchers face the problem of getting manuscripts written by them published in reputed journals. Today, the word processing software and digital literature sources have changed our ways of writing on the results of research projects conducted by the researchers. However, these technologies should not be utilized to alter the basic requirements of writing a qualitative research paper which follows the accepted academic standards for citations, style, logical presentation of the results, scientific discussion and format.

Most of us rather read than write. However, you need to be ready to plan your first draft of the research paper, after being satisfied with the storyboard you are going to present. You need to have sufficient facts and confidence that you can sketch a reasonable case to support your hypothesis developed. As a young researcher, it is better to draft your paper first, develop your notes into the elements of a research argument and secondly, organize these elements into a rational form. Once you bring your argument together, you are ready to write the first draft.

Some young researchers do a big mistake in writing a research paper; that is organizing the research paper as a narrative of the research project. Readers want to see your thinking and what you are adding to the knowledge. Especially, the part of introduction of the research or review paper needs to be very attractive and eye catching. Therefore, you have to write the introduction section from the readers' perspective. You need to introduce a specific research that you intend to extend, describe and forward to the readers. Then, use a good logical order probably, chronological, that causes to effect or make comparison to contrast or etc.

The Journal of Agricultural Sciences adds a sub title from this issue. In future, the journal is titled as the 'Journal of Agricultural Sciences- Sri Lanka' enabling to distinguish it from other journals with similar titles. The format of the abstract of the papers has also been changed and authors have to submit writings according to the new format of appears in this issue. Further, the Editorial Committee of the journal is reappointed from this issue with the inclusion of a number of renowned researchers in the global academia. All these efforts are to receive the highest recognition for the journal by getting indexing in SCOPUS and elementary SCI.

Therefore, I would like to remark the fact that JAS publishes only high quality research manuscripts with some contribution to the knowledge of science. At present, the JAS has been included in more than 35 journal databases including AGRICOLA, AGORA, Cabi Abstracts, TEEL and DOAJ. This shows the wider acceptance of JAS by international citations and journal databases. This is an indicator of our progress in maintaining the quality of the journal during past years. There were many people behind this success. This honour must go to Dr. Chandrika Dissanayake - Coordinating Editor of JAS, Mr. Prasad Iddamalgoda- Editorial Assistant, Ms. Suiox Cummings and Andy Nobes of SLJOL, Mr. Harsha Udayakantha Peiris- Copy Editor, all the authors, reviewers and the members of the Editorial Committee.

Prof. Dr. Rohana P Mahaliyanaarachchi

Editor in Chief

$01^{\text {st }}$ January 2018

http://dx.doi.org/10.4038/jas.v13i1.8295 